\title{
Risks and benefits of coronary angioplasty: the patient's perspective: a preliminary study
}

\author{
Frank Kee, Penny McDonald, Brian Gaffney
}

\begin{abstract}
Objectives-To describe what cardiac patients in Northern Ireland understand to be the benefits of coronary angioplasty and assess the extent to which they have been able to make informed choices about their treatment.

Design-An interview based questionnaire survey completed after the patients had undergone coronary angiography, within hours of treatment counselling. Subjects-150 patients consecutively recruited from two regional cardiology centres in Belfast, Northern Ireland.

Main outcome measures-The perceived complication rate and the perceived gain in life expectancy from coronary angioplasty.
\end{abstract}

Results-Although most subjects had asked the consultant questions, $70 \%$ $(n=104)$ thought that they contributed negligibly or not at all to the treatment decision. Although $75 \%(n=112)$ recalled discussing the complication rate from the procedure, only $27 \%$ accurately estimated this rate (as between 0.5 and $1.5 \%$ ). Eighty eight per cent $(n=131)$ thought that their mortality risks would be substantially or greatly reduced by having the procedure. The patients anticipated a gain in life expectancy of some 10 years (median) and this was significantly in excess of the potential gain in life expectancy which dietary prudence to lower blood cholesterol, not smoking, and taking more exercise might produce (median 5 years respectively; $\mathbf{P}<0.0001$, Wilcoxon matched pairs signed rank test).

Conclusions-Patients vastly overrate the capacity of angioplasty to control their disease: angioplasty is seen as more effective than risk factor modification.

(Quality in Health Care 1997;6:131-139)

Keywords: angioplasty; patients' perceptions

Social Services Board and Northern Ireland Health Promotion Agency

Brian Gaffney, consultant in public health medicine

Correspondence to:

Dr Frank Kee, Department of Epidemiology and Public Health, the Queen's

University of Belfast,

Mulhouse Building, Royal

Victoria Hospital, Grosvenor

Road, Belfast BT 12 6BJ,

Northern Ireland, UK.

Accepted for publication 25 June 1997 Despite the fact that the experience of undergoing coronary angioplasty or bypass surgery is often a trigger for cardiac patients to improve their lifestyle (by, for instance, giving up smoking or losing some weight), many will backslide without intensive support from family, friends, or their doctor. Two recent meta-analyses have sought to identify the particular features of educational programmes, or of the patients themselves, that might predict successful long term behavioural change. ${ }^{12}$ Although there may be reason to doubt the use of straightforward advice giving, ${ }^{3}$ and it seems natural to assume that patients already know about the dangers of smoking and sloth, there is evidence that knowledge and health beliefs can affect behaviour. ${ }^{4}$ For example, in a study of compliance with cardiac rehabilitation, a health belief model (which reflected the patients' thoughts about severity of disease and their perceptions of the effectiveness of exercise) accounted for a considerable proportion of the variance in dropout rates. ${ }^{6}$ The debate about the magnitude of this sort of effect may stem from various meanings given to knowledge, for although patients appreciate that certain lifestyles confer risk, their propensity for change in behaviour or compliance with treatment may be affected by their perceptions of the relative efficacy of the treatment (or prevention) options..$^{7-10}$

It is surprising that these have seldom been studied for it seems clear that patients and some doctors have unrealistic expectations of the efficacy and benefits of, for example, bypass surgery. ${ }^{11}$ That this itself may be detrimental to health was suggested in a study of psychological morbidity among patients on a waiting list, which concluded that preoperative anxiety may be related to the high expectations of the outcome after surgery. ${ }^{12}$ The authors suggested that this might be alleviated by better counselling and communication about the risks and benefits of the procedure.

Furthermore, patients who have not grasped the risks and benefits of various treatment or prevention options are not able to give properly informed consent. Though this issue has been the focus of recent editorials and reviews dealing with entry to clinical trials ${ }^{1314}$ it may have wider salience to the place of standard treatment when the benefits of accepted alternatives have not been properly understood. A study of patients awaiting bypass surgery and angioplasty found that the risks of the procedures were very poorly understood, but concluded that because patients are confident in their doctor's treatment decisions, a degree of paternalism may be justified. ${ }^{15}$ Such a conclusion would only be appropriate if the 
doctors and patients had a comparable appreciation of the benefits of intervention and how the outcomes might be valued in the context of alternative treatment strategies. Indeed, a particular focus of the Department of Health's own research and development strategy is now focusing on enhancing consumer participation in medical decision making, building on a growing literature which seems to point to the possibility of empowerment processes affecting clinical outcomes. ${ }^{16}$

This study has been designed to describe what cardiac patients in Northern Ireland understand to be the benefits of coronary angioplasty and to assess the extent to which they have been able to make informed choices about their treatment.

\section{Methods}

One hundred and fifty patients who were to have elective coronary angioplasty (at either of the two regional cardiology centres in Belfast) were recruited for this preliminary study and interviewed by a research nurse within 24 hours of having their initial angiography. An interview based questionnaire was completed by a research nurse usually within hours of the patient having been counselled by the consultant about the proposed management plan. Patients were not approached unless able to give consent to the study-that is, after any effects of premedication had worn off). Patients were recruited consecutively between February and October 1995. During this period the main reasons for non-participation $(n=30)$ were logistical, most often because the patient had been discharged early after angiography and was not available when the nurse attended the ward. Only one patient refused to be interviewed. Patients were drawn from the clinical practice of 13 different cardiologists, who had all seen and approved the study protocol before consenting to the study of their patients. It was not routine practice for any of these doctors to give their patients explicit written information about the effect of angioplasty on prognosis.

Sociodemographic and clinical data were recorded before the interview. The patients were then asked about how they obtained information about angioplasty and other medical treatments for their heart condition and about how they viewed the risks and benefits. (The appendix shows the key sections of the questionnaire.) Patients were also asked how satisfied they were with the care they had received from the consultant and whether they thought that they themselves had contributed significantly to the choice of management plan.

The information was checked, coded, and entered on to an SPSS for windows database. Comparisons of the anticipated benefits of preventive treatment were made with the Mann-Whitney $U$ test and the Wilcoxon matched pairs signed rank tests for nonnormally distributed data. The magnitude of the perceived benefits was compared across categories of patients with the $\chi^{2}$ test for contingency tables.
Table 1 Baseline demographic and clinical characteristics

\begin{tabular}{lrl}
\hline Characteristics & $n$ & $(\%)$ \\
\hline Sex: & $n$ & \\
Male & 112 & $(75)$ \\
Female & 38 & $(25)$ \\
Age (y): & & \\
$<49$ & 32 & $(21)$ \\
$50-9$ & 62 & $(41)$ \\
$\quad \geqslant 60$ & 56 & $(38)$ \\
Education (y): $†$ & & \\
$<14$ & 68 & $(45)$ \\
$15-7$ & 66 & $(44)$ \\
$\quad \geqslant 18$ & 16 & $(11)$ \\
Angina grade: $¥$ & & \\
I/II & 21 & $(14)$ \\
III / IV & 118 & $(79)$ \\
Atypical & 11 & $(7)$ \\
\hline
\end{tabular}

${ }^{\star}$ Age at angiography.

†Number of completed years full time education.

$\ddagger$ At referral to cardiologist.

Canadian Cardiovascular Society grading scale for angina ${ }^{30}$ : class $I=$ ordinary physical activity does not cause angina: no angina occurs when walking or climbing stairs; angina does occur with strenuous or rapid or prolonged exertion at work or recreation; class II=slight limitation of ordinary activity: angina occurs when walking or climbing stairs rapidly; walking uphill; walking or stair-climbing after meals, in the cold, in the wind, under emotional stress, or only during the first few hours after awakening; walking more than two blocks on the level; and climbing more than one flight of ordinary stairs at a normal pace and in normal conditions; class III=obvious limitation of ordinary physical activity: angina occurs when walking one or two blocks on the level and climbing one flight of stairs in normal conditions and at a normal pace; class IV=inability to carry on any physical activity without discomfort, anginal syndrome may be present at rest.

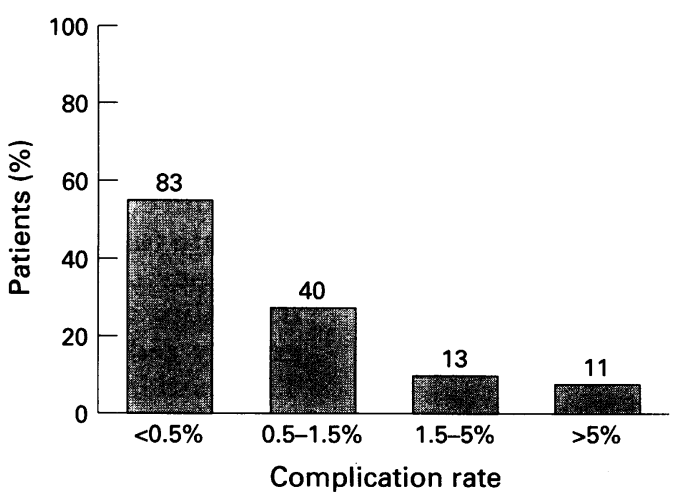

Figure 1 Patients' perceptions of the major complication rate of angioplasty.

This study was approved by the research ethics committee of the Queen's University of Belfast.

\section{Results}

The age range of the patients was 37-77 years (median 57; mean 57; SD 8.7). Seventy five per cent were men, the mean number of years of full time education was 15 , and $79 \%$ had Canadian Cardiovascular Society grade III or IV angina (table 1). Although $76 \%(n=113)$ of patients had asked their consultant questions about their treatment (during counselling after angiography), ultimately $70 \% \quad(n=104)$ thought that they contributed negligibly or not at all to the treatment decision. Although $75 \%$ $(n=112)$ recalled discussing the complication rate from the procedure, only $27 \%$ accurately estimated this rate (as between 0.5 and $1.5 \%$ ), most of the rest tended to give an underestimate (less than $0.5 \%$, fig 1 ).

Most $(77 \%(n=114))$ anticipated regaining a normal (or a substantial improvement in) 

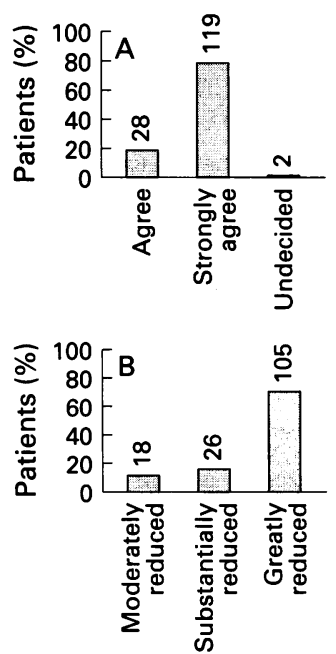

Figure 2 Patients' perceptions of the efficacy of angioplasty in reducing mortality. $(A)$

"Undergoing angioplasty will lower my risk of dying prematurely and help me to live longer." (B) Degree to which mortality risks will be reduced. quality of life after angioplasty and $88 \%$ $(n=131)$ thought that their mortality risks would be substantially or greatly reduced (fig $2 \mathrm{~A}$ and $\mathrm{B})$. By having the procedure, the patients anticipated a gain in life expectancy of some 10 years (median; range $0-40$ years) and this was significantly in excess of the potential gain in life expectancy which dietary prudence to lower blood cholesterol, not smoking, and taking more exercise might produce (range $0-30$ years, $0-20$ years, and $0-30$ years respectively; median five years respectively; $P<0.0001$, Wilcoxon matched pairs signed rank test (fig 3). Based on several recent reviews, these estimates are nevertheless all materially in excess of what the available evidence would point to as the likely benefits (table 2).

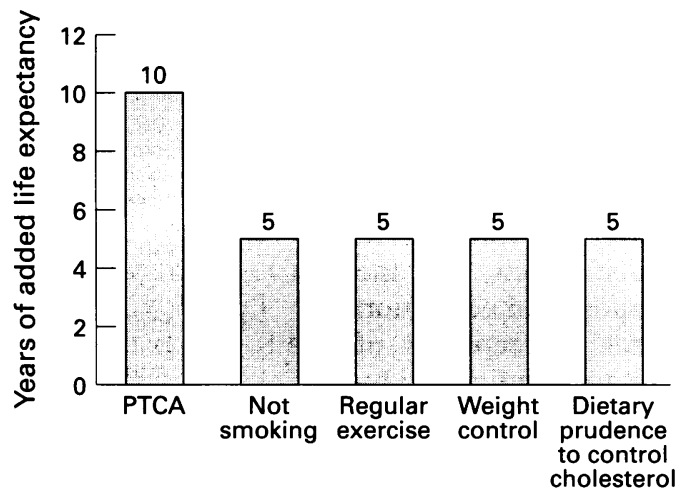

Figure 3 Perceived gain in life expectancy from angioplasty and modification of risk factor.

However, most of these patients (99\%; $\mathrm{n}=149$ ) were satisfied with the treatment they were receiving and the magnitude of the perceived benefits of treatment were unrelated to the patients' educational level, whether they had asked questions during the counselling session, and their degree of satisfaction with the consultant's care (data not shown).

\section{Discussion}

These data suggest that cardiac patients have overrated expectations of what both revascularisation and secondary prevention advice can offer them after angioplasty. However, it seems that the perceived efficacy of modern medical treatments such as angioplasty overshadows the perceptions of how a healthy lifestyle can benefit. Furthermore, the same patients tend to underestimate the complication rate from angioplasty. In our discussions with the con-

Table 2 Anticipated gains in life expectancy from modification of risk factors

\begin{tabular}{lll}
\hline & \multicolumn{2}{l}{ Gains in life expectancy $(y)$} \\
\cline { 2 - 3 } Risk factor modified & Men & Women \\
\hline Stopping smoking $^{31 \star}$ & $1.2-2.3$ & $1.5-2.8$ \\
Cholesterol control $^{31 \star}$ & $0.5-4.2$ & $0.4-6.3$ \\
Weight control $^{31 \star}$ & $0.7-1.7$ & $0.5-1.1$ \\
Participation in exercise $^{32} \dagger$ & $0.1-1.3$ & NA \\
$\begin{array}{l}\text { Participation in exercise } \\
\text { and stopping smoking }\end{array}$ & $1.3-3.7$ & NA \\
\hline
\end{tabular}

${ }^{\star}$ Gains in life expectancy for 35 year olds at risk. +Gains in life expectancy for men aged over 45 to 84 free from coronary heart disease. $\mathrm{NA}=$ not available. sultants, we know that it is standard practice to routinely discuss the possible complications and give some estimate of their rate, so even though our interviews with the patients were conducted within hours of their treatment counselling, it is possible that the patients' faulty recall could at least partly account for this finding. Although the consultants rarely, if ever, claimed to have made estimates of how angioplasty might affect mortality rates, the patients seem to be left, albeit indirectly, with the impression of considerably improved life chances. Given that no study has yet shown that, compared with medical treatment, angioplasty can reduce mortality risks, does this stem from a "hope springs eternal" frame of mind on the part of the patients, or does it reflect more on their inherent confidence in the capabilities of their consultant and his or her decisions? Logistically it was not possible for us to audiotape the doctor-patient counselling sessions but perhaps such efforts might shed light on the source of the patient's misperceptions.

Although we have no specific information on the perceptions of these consultants, doctors are no less subject than patients to cognitive biases in their perceptions of the value of different treatments. For example, in the multicentre bypass angioplasty revascularisation investigation, ${ }^{17}$ comparisons across centres and among readers showed that the most important factor determining eligibility for the trial was the angiographer's degree of confidence in the efficacy of angioplasty, this despite the fact that there was agreement between readers in only $28 \%$ of cases and when blindly rereading the films the operators agreed with their earlier assessments only $73 \%$ of the time. Furthermore, cardiologists undertaking angioplasty systematically overestimate the degree of pretreatment luminal stenosis and underestimate the residual stenosis, tending to produce a biased view of treatment success. ${ }^{18} 19$

There are some who think that physicians "must strike a balance between submerging their patients in information, thereby diminishing their patients' ability to make rational choices and restricting that information to simplify decision making". ${ }^{20}$ It is sometimes claimed that open discussion of the benefits and the risks of treatment might cause undue anxiety or make the reporting of side effects more likely. That this is unlikely to be the case was elegantly shown in a recent randomised controlled trial. ${ }^{21}$ However, it should not be assumed that patients will have any more difficulty than their physicians in interpreting outcome data. ${ }^{22}{ }^{23}$ Even now, much of the debate has focused on the need for consent procedures to deal openly with risks without any apparent explanation on the relative benefits. ${ }^{24}$

If the health belief model does have relevance for changes in lifestyle and behaviour then it is important to assess both the framing and the format in which the benefits of preventive treatments have been communicated ${ }^{25}$ and the perceptions about the relative efficacies of different interventions. This has hardly ever been done. Although our patients knew about 
the wisdom of a prudent lifestyle, they are little different from some doctors in their overestimation of the potential gains in life expectancy. ${ }^{26}$ However, it will be important to determine whether those who relatively overvalued angioplasty the most are any less likely than those with more realistic expectations to adopt healthier lifestyles. This will require a prospective study. To date, one very small cross sectional study $(n=14)$ concluded that the relative ease of the angioplasty procedure could act to decrease patients' motivation to reduce known cardiac risk factors. ${ }^{27}$ However, a recent systematic review suggests that there is a significant relation between the effectiveness of the communication process and improved health outcomes. ${ }^{28}$

It would seem sensible, therefore, to ensure that future research on evaluating standards to support patients' decisions ${ }^{29}$ must also assess the impact of expectancy on healthcare outcomes. It is unclear, for instance, whether patients with positive but unrealistic expectations of their treatment (as in the case of coronary artery bypass surgery and angioplasty) ultimately do better or worse than those holding a more realistic view, but the implications for patient support and education might be different. Patients' perceptions of health state and preferences are conditioned by the difference between what is and what they consider might have been.

We are grateful to Mary McConville and Hazel Johnston for conducting the interviews, to all the cardiologists at the Royal Victoria Hospital and the Belfast City Hospital for permission to and Stroke Association for funding the study.

1 Godin G. The effectiveness of interventions in modifying behavioural risk factors of individuals with coronary hear disease. F Cardpulm Rehabil 1989;9:223-36.

2 Mullen PD, Mains D, Velez R. A meta-analysis of controlled trials of cardiac patient education. Patient Education and Counselling 1992;19:143-62.

3 Rollnick S, Kinnersley P, Stott N. Methods of helping patients with behaviour change. BMf 1993;307:188-90.

4 Rolloick S, Heather N, Bell A. Negotiating behaviour change in medical settings: the development of brief motivational interviewing. $\mathcal{J}$ Mental Health 1992;1:25-37.

5 Eraker S, Becker M, Strecher V, Kirscht JP. Smoking behaviour iour, cessation techniques and

6 Oldridge N, Streiner DL. The health belief model: predicting compliance and drop-out in cardiac rehabilitation. $M e d$ ing compliance and drop-out in carc

7 Rothert M, Rovner D, Holmes M, Schmitt N, Talarczyk G, Kroll J, et al. Womens use of information regarding hormone replacement therapy. Res Nurs Health 1990;13: 355-66.
8 Wills C, Moore C. Judgement processes for medication acceptance: self reports and configural information use. Med Decis Making 1994;14:137-45.

9 McNeil B, Pauker S, Sox H, Tversky A. On the elicitation of preferences for alternative therapies. $N \mathrm{Engl} f \mathrm{Med}$ 1982;306:1259-62.

10 Hux JE, Naylor CD. Communicating the benefits of chronic preventive therapy: does the format of efficacy data determine patient's acceptance of treatment? Med Decis Making 1 995;15:152-7.

11 Kee F, Gaffney B, Canavan C, Little J, McConnell W, Telford AM, Watson JD. Expanding access to coronary artery bypass surgery: who stands to gain? Br Heart $\mathcal{f} 1994 ; 73$ : 129-33.

12 Underwood MJ, Firmin RK, Jehu D. Aspects of psychological and social morbidity in patients awaiting coronary cal and social morbidity in patients awaiting

3 Horton R. The context of consent. Lancet 1994;344:211-2.

4 Wager E, Tooley PJ, Emanuel M, Wood S. How to do it: get patients' consent to enter clinical trials. BMF 1995;311: 734-7.

15 Weston C, Watura R, Reeves P, Fraser A. Do patients with heart disease sanction medical paternalism [abstract 237]. Br Heart f 1993;(suppl):54

$16 \mathrm{Kee}$ F. Patients prerogatives and perceptions of benefit. $B M \mathcal{F}$ 1996;312:958-60.

17 Wisiewski S, Kelsey S, Ohman M. Angiographic eligibility assessment in the bypass angioplasty revascularisation assessment in the bypass angioplasty revasculati
investigation. Control Clin Trials 1995;16:1245-55.

18 Kimball B, Bui S, Cohen E, Cheung P, Lima V. Systematic bias in the reporting of angioplasty outcomes: accuracy of visual estimates of absolute lumen diameters. Can $\mathcal{F}$ Cardiol 1994;10:815-20.

19 Goldberg RK, Leiman NS, Minor ST, Abukhalil J, Raizner AE. Comparison of quantitative coronary angiography to visual estimates of lesion severity pre and post PTCA. Am Heart f 1990;119:178-84.

20 Honon R. The context of consent [editorial]. Lancet 1994;344:211-2

21 Lamb G, Green S, Heron J. Can a physician warn patients of potential side effects without causing fear of those side potential side effects without causing fear

22 Naylor CD, Llewellyn-Thomas HA. Can there be a more patient-centred approach to determining clinically imporpatient-centred approach to determining clinically imporEpidemiol 1994;47:787-95.

23 McNeil BJ, Pauker S, Six H, Tversky A. On the elicitation of preferences for alternative therapies. $N \mathrm{Engl} f \mathrm{Med}$ 1982;306:1259-62

24 Langford E, de Belder A. Consent procedure for coronary angioplasty is haphazard [letter]. $B M \mathcal{F} 1997 ; 314: 1762$.

25 Hux J, Naylor CD. Communicating the benefits of chronic preventive therapy: does the format of efficacy data determine patients' acceptance of treatment? Med Decis Making 1995;15:152-7.

26 Grover S, Lowensteyn I, Esrey K, Steinen Y, Joseph L, Abrahamowicz M. Do doctors accurately assess coronary Abrahamowicz $\mathrm{M}$. Do doctors accurately assess coronary risk in their patients? Preliminary results of the

27 Gaw BL. Motivation to change life-style following PTCA. Dimens Critical Care in Nursing 1992;11:68-74.

28 Stewan M. Effective physician-patient communication and health outcomes: a review. Can Med Assoc F 1995;152: 1423-33.

29 Holmes-Rovner M. Evaluation standards for patient decision supports. Med Decis Making 1995;15:2-3

30 Cox J, Naylor CD. The Canadian Cardiovascular Society grading scale for angina pectoris: is it time for refinements? Ann Intern Med 1992;117:677-83.

31 Tsevat J, Weinstein MC, Williams LW, Tosteson ANA, Goldman L. Expected gains in life expectancy from various Goldman $L$. Expected gains in life expectancy from various 1991;83:1194-201.

32 Paffenbarger RS, Hyde RT, Wing AL, Lee IM, Jung DL, Kampert JB. The association of changes in physical-activity level and other lifestyle characteristics with mortality among men. $N$ Engl $\mathcal{F}$ Med 1993;328:538-45. 
For the average smoker of your age with coronary heart disease what would you consider are the benefits of giving up.

Please indicate your views on the following statements:

For office use only

Smokers who give up would lower their risk of dying and help them to live longer (Please circle) 5 Strongly agree 4 Agree 3 Undecided 2 Disagree 1 Strongly disagree

To what degree?

(SHOWCARD 6)

5 Greatly reduced risks of premature mortality

4 Substantially reduced mortality risks

3 Moderately reduced mortality

1 No effect on mortality risks

How many extra years of life would you guess that a smoker of your age with coronary heart disease might have by giving up the habit? (ie the ADDITIONAL rather than just the remaining years)

\begin{tabular}{l|l|l|l}
\multicolumn{1}{c}{ Years } & \multicolumn{1}{c}{ Months } \\
\cline { 2 - 3 } Men & & & $\begin{array}{l}\text { Code total in months } \\
\text { Women }\end{array}$ \\
\cline { 2 - 3 } & & &
\end{tabular}

If a smoker or an ex-smoker, how many extra years of life would you estimate that YOU might gain, by

giving up the habit?
(if a never smoker, code 88 ) (ie the ADDITIONAL rather than just the remaining years)

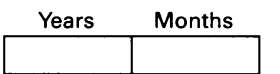

Code total in months

(SHOWCARD 5 )

Smokers who give up would have a better quality of life

5 Strongly agree

3 Undecided

(Please circle)

If a smoker, or an ex-smoker, do you agree that you would have or have had a better quality of life by/since giving up?

(if a never smoker, code 88)

5 Strongly agree $\quad 4$ Agree $\quad 3$ Undecided 2 Disagree 1 Strongly disagree

(SHOWCARD 5 )

\section{Physical activity}

Compared to other people of your age would you describe yourself as....

(Please circle)

Now

1 Very physically active

2 Fairly physically active

3 Not very physically active

4 Not at all physically active

Before the onset of your heart problem

1 Very physically active

2 Fairly physically active

3 Not very physically active

Have your family or friends encouraged or discouraged you to take more physical exercise?

("since recovering from your coronary", if appropriate)

Encouraged a lot

Encouraged a little

Neither

Discouraged a little

Discouraged a lot

Has your doctor ever encouraged or discouraged you to take more physical exercise?

("since recovering from your coronary", if appropriate)

Please use one of the following codes:

$1=$ Encouraged a lot: $2=$ Encouraged a little; $3=$ Neither; $4=$ Discouraged a little; $5=$ Discouraged a lot

Who has so advised you?

If yes, what advice

Cardiologist 1 Yes 2 No

GP

When was advice in this regard last given to you?

$$
\text { (date) }
$$

For the average person of your age with coronary heart disease what would you consider would be the benefits of taking more regular exercise:

Please indicate your views on the following statements.

Taking more exercise would lower the risks of dying and help them to live longer

(SHOWCARD 5)

5 Strongly agree

$$
4 \text { Agree } 3 \text { Undecided }
$$

2 Disagree

1 Strongly disagree

\section{(SHOWCARD 6)}

5 Greatly reduced risks of premature mortality

4 Substantially reduced mortality risks

2 A little lower mortality risks

1 No effect on mortality risks

How many years of extra life would you guess that a usually inactive patient of your age with coronary heart disease might gain by taking more exercise ? (if so advised by the doctor)

(ie the ADDITIONAL rather than just the remaining years)

(Please code "0" if you think that life expectancy would not be altered)

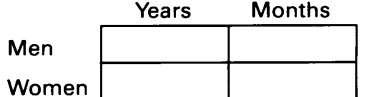

Code total in months Code total in months 
If I took more exercise, (on medical advice), I would lower my mortality risks and live longer (Please circle) SHOWCARD 5)

5 Strongly agree $\quad 4$ Agree $\quad 3$ Undecided 2 Disagree 1 Strongly disagree

For office use only

How many years of extra life would you guess that YOU might gain by taking more exercise ? the remaining years

\begin{tabular}{|l|l|}
\hline Years & \multicolumn{1}{c}{ Months } \\
\hline & \\
\hline
\end{tabular}

Code total in months ADLIEXP

Those who take more physical exercise would enjoy a better quality of life (Please circle) (SHOWCARD 5)

5 Strongly agree 4 Agree 3 Undecided 2 Disagree 1 Strongly disagree

If I took more physical exercise I would enjoy a better quality of life

5 Strongly agree $\quad 4$ Agree 3 Undecided 2 Disagree

(SHOWCARD 5)

\section{Weight control}

Do you consider yourself to be overweight?

$$
1 \text { Yes } 2 \text { No }
$$

1 Strongly disagree

EXPAQU

Since the age of 18 what is the heaviest weight you have ever been ? (that was not attributable to illness)

OVWT

Since the age of 8 what is the heaviest weight you have ever been ? (that was not attributable to illness)

HEWT18

Since the onset of your heart problem, has a doctor ever advised you to lose weight? $\quad$ (Please circle)

Who has so advised you?

Cardiologist 1 Yes 2 No

CAADWT

GPADWT

Since the onset of your heart problem has a doctor ever advised you to attend a supervised weight-loss programme (eg a "weight-watchers" class) (Please circle)

$$
1 \text { Yes } 2 \text { No }
$$

Since the onset of your heart problem has a doctor ever referred you to a dietitian ?

$$
1 \text { Yes } 2 \text { No }
$$

Have you ever tried to lose weight for the benefit of your health ?

$$
1 \text { Yes } 2 \text { No }
$$

For an overweight person of your age with coronary heart disease what would you consider

to be the benefits of losing weight or maintaining a normal weight.

Please indicate your views on the following statements.

Coronary heart disease patients who achieved a normal weight would lower their risks of dying and live longer

5 Strongly agree 4 Agree 3 Undecided 2 Disagree 1 Strongly disagree

To what degree? (SHOWCARD 6)

5 Greatly reduced mortality risks of premature mortality

4 Substantially reduced mortality risks

3 Moderately reduced mortality

1 Alittlower mortality risks

How many years of extra life would you guess that a person of your age with coronary heart disease, who was substantially overweight might gain by achieving a more normal weight

(ie the ADDITIONAL rather than just the remaining years)

(Please code "0" if you think that life expectancy would not be altered)

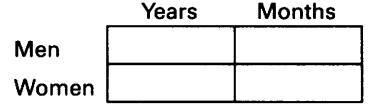

By maintaining a normal weight / could lower my risk of dying prematurely and live longer (SHOWCARD 5) (Please circle)

5 Strongly agree

$$
4 \text { Agree }
$$

3 Undecided

2 Disagree

1 Strongly disagree

How many years of extra life would you guess that YOU might gain by maintaining a normal weight? (ie the ADDITIONAL rather than just the remaining years)

(Please code " 0 " if you think that life expectancy would not be altered)

\begin{tabular}{|l|l|}
\multicolumn{1}{c}{ Years } & \multicolumn{1}{c}{ Months } \\
\hline & \\
\hline
\end{tabular}

Code total in months ADLIEXNO

\section{Dietary habits}

Has a doctor ever advised you to consume a healthier diet, ie a lower fat diet to control your blood cholesterol ?

Who has so advised you ?

$\begin{array}{lll}\text { Cardiologist } & 1 \text { Yes } & \text { No }\end{array}$ 
Do you know or have you ever asked your doctor about your cholesterol level ?

$$
1 \text { Yes } 2 \text { No }
$$

Have you ever tried to take a healthier diet that was lower in fat content?

$$
1 \text { Yes } 2 \text { No }
$$

For office use only $\mathrm{CHOL}$

(Please circle)

For a person of your age with coronary heart disease what would you consider are the benefits of eating a healthier diet to achieve/maintain a normal blood cholesterol ?

Please indicate your views on the following statements.

Patients with coronary heart disease who ate a lower fat diet to control their cholesterol would lower their risks of dying and live longer (Please circle)

5 Strongly agree 4 Agree 3 Undecided 2 Disagree 1 Strongly disagree

(SHOWCARD 5)

To what degree?

(SHOWCARD 6)

5 Greatly reduced mortality risks of premature mortality

4 Substantially reduced mortality risks

3 Moderately reduced mortality risks

2 A little lower mortality risk

1 No effect on mortality risks

How many years of extra life would you guess that a person with coronary heart disease of your age might gain by reducing the amount of fat in the diet to control blood cholesterol ?

(Please code " 0 " if you think that life expectancy would not be altered)

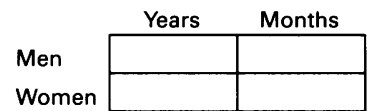

Code total in months

Code total in months

(SHOWCARD 5)

If I ate a lower fat diet to control my cholesterol, I would lower mortality risks and live longer.

5 Strongly agree $\quad 4$ Agree $\quad 3$ Undecided $\quad 2$ Disagree 1 Strongly disagree

How many years of extra life would you guess that YOU might gain by eating/maintaining a lower fat diet to control blood cholesterol? (ie the ADDITIONAL rather than just the remaining years)

(Please code "0" if you think that life expectancy would not be altered)

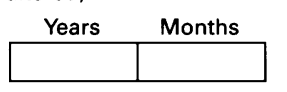

Code total in months ADLILOFA

PRIOR TO ANGIOPLASTY (AFTER ANGIOGRAPHY)

THIS SECTION IS TO BE COMPLETED AFTER THE TREATMENT OPTIONS HAVE BEEN DISCUSSED WITH THE PATIENT BY

THE DOCTOR IN CHARGE, OR HIS NOMINATED DEPUTY.

Have you ever discussed with the doctor the results of your angiography test and the treatment

options for your heart disease?

$$
1 \text { Yes } 2 \text { No }
$$

With whom did you discuss this?

1 Cardiologist

2 Sen R

$\begin{array}{lll}1 \text { Yes } & 2 \text { No } \\ 1 \text { Yes } & 2 \text { No }\end{array}$

$\begin{array}{ll}1 \text { Yes } & 2 \text { No } \\ 1 \text { Yes } & 2 \text { No }\end{array}$

Was a decision reached on the best treatment option for you ?

(Please circle)

$$
1 \text { Yes } 2 \text { No }
$$

Were you given an opportunity to ask questions about the treatment options ?

$$
1 \text { Yes } 2 \text { No }
$$

Did you ask the doctor any questions about the treatments available?

$$
1 \text { Yes } 2 \text { No }
$$

BESTRE

Did you contribute to the decision on the preferred treatment option? (Please circle)

5 My decision entirely

4 Substantially my decision

3 My decision to some extent

2 My decision to a negligible extent
1 Not my decision at all

In your opinion, which doctor gave you most information about the treatment you are about to receive?

1 Cardiologist (consultant) 2 SR/Reg $\quad 3$ SHO 4 JHO 5 Other

(SHOWCARD 8)

In general, how serious do you consider your present illness to be?

(Select one response from the following)

5 Very serious

4 Moderately serious

3 Somewhat serious

2 Not very serious

1 Not at all serious

Have you been told the number of coronary arteries that have significant disease?

$$
1 \text { Yes } 2 \text { No }
$$

Can you tell me? 
How likely do you think it is that you could get this illness or problem again ?

5 Very likely

4 Moderately likely

Somewhat likely

1 Not at all likely

In general, how satisfied have you been with the care that you have received from your consultant?

5 Very satisfied

Moderately satisfied

Neither satisfied nor dissatisfied

Moderately dissatisfied

1 Very dissatisfied

In general, how friendly do you feel the consultant who supervised your treatment is?

5 Very friendly

4 Moderately friendly

3 Neither friendly nor unfriendly

2 Moderately unfriendly

1 Very unfriendly

\section{In regard to angioplasty}

Was information provided about effects of the procedure on mortality risks from coronary heart disease or overall mortality?

$$
1 \text { Yes } 2 \text { No }
$$

(SHOWCARD 9)

(SHOWCARD 10)

RECUR

For office use only

SATISF

(SHOWCARD 11)

FRIEND

ANGINFO

What is your impression now of the anticipated benefits of having this procedure?

Undergoing angioplasty will lower my risks of dying prematurely and help me to live longer

5 Strongly agree $\quad 4$ Agree $\quad 3$ Undecided 2 Disagree 1 Strongly disagree

(SHOWCARD 5)

To what degree?

(SHOWCARD 6)

5 Greatly reduced mortality risks of premature mortality

4 Substantially reduced mortality risks

3 Moderately reduced mortality risks

2 A little lower mortality risks

What is your impression now of the anticipated benefits of having this procedure, in terms of the

potential to increase your life expectancy?

Added life expectancy

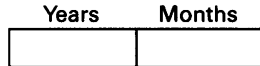

Code total in months

Was information provided about effects on quality of life?

$$
1 \text { Yes } 2 \text { No }
$$

What is your impression now of the anticipated benefits of having this procedure?

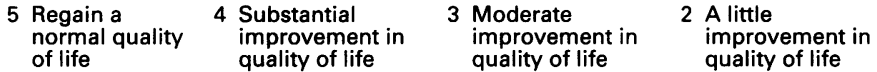
normal quality improvement quality of life quality of life
1 No

improvement in quality of life

How likely would you say it was that you would reap the health benefits described above (SHOWCARD 13) by undergoing this procedure?

7 Health benefits guaranteed

6 Very likely

5 Moderately likely

Somewhat likely

Not very likely

No chance at al

Was information provided about any possible risks from this procedure (as opposed to from the CHD) ?

$$
1 \text { Yes } 2 \text { No }
$$

ANGPEBE

Are you aware of any complications from this form of therapy?

$$
1 \text { Yes } 2 \text { No }
$$

If yes, please specify?

What is your impression of the complication rate from this therapy (Out of every 100 patients, what percentage might you guess would have a major complication)?
$1<0.5 \%$
$20.5 \%-1.5 \%$
$3>1.5$ and $<5 \%$

$$
4>5 \%
$$

Heart disease is very common in Northern Ireland. This cardiac unit performs hundreds of angioplasties each year and so not every patient can have their treatment immediately. If you were among 10 patients clinical priority for treatment? 1 eg $1=$ most urgent and (Prompt and clarify to ensure task is understood) 
To help people say how good or bad a health state is, we have drawn a scale on which the best possible state you can imagine is marked by 100 and the worst state you can imagine is marked by 0 . We would

like you to indicate on this scale how good or bad your own health is today, by drawing a line on this scale.

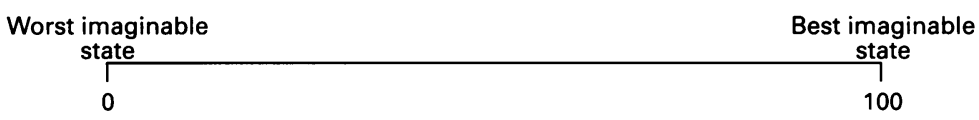

Now if, for whatever reason, you were unable to have your angioplasty until six months from now, what would you anticipate would be your health state by that time?

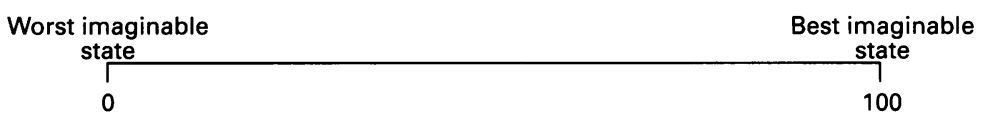

After angioplasty has been performed.....prior to discharge

With whom have you spoken about your treatment since undergoing the procedure?

$\begin{array}{lll}1 \text { Cardiologist } & 1 \text { Yes } & 2 \text { No } \\ 2 \text { SR/Reg } & 1 \text { Yes } & 2 \text { No } \\ 3 \text { SHO } & 1 \text { Yes } & 2 \text { No } \\ 4 \text { Other } & 1 \text { Yes } & 2 \text { No }\end{array}$

Based on what you have been told, how successful do you feel the treatment has been in clearing the blockage in your coronary artery?

Indicate how successful on a scale of 1 to 5 :

5 Completely

4 Substantially

Moderately

2 A little

1 Not at all

Heart disease is very common in Northern Ireland. This cardiac unit performs hundreds of angioplasties each year and so not every patient can have their treatment immediately. What factors would you consider it reasonable for cardiologists to take account of, when deciding who should receive relatively higher priority? There is no right or wrong answer and it is your own views which are important to us. Apart from the specific factor indicated, consider that the groups being compared are similar in other respects, including disease severity.

(Please circle) Increased priority Decreased priority No different

Severity of symptoms

(more $v$ less severe)

Gender

1

1

23

3

(male $v$ female patients)

Obesity

(obese $v$ non-obese patients)

Smoking habit

(smokers $v$ non-smokers)

Employment

(breadwinners $v$ non-breadwinners)

3

Number of dependants

(those with dependant children $v$ those without)

Age

(relatively young $v$ older subjects)

1

1

1

1

12

1

If response "1" or "2" is selected, what age would be considered the lower limit of the "older" age group ?
SYMPRI

For office use only

\section{STATENOW}

STATESIX

POSTCARD

POSTREG

POSTSHO

SUCCFEEL

GENPRI

OBESPRI

SMOKPRI

EMPLPRI

DEPENPRI

AGEPRI

AGELIM 